Research Article

\title{
Correlation of Sunlight Exposure and Different Morphological Types of Age-Related Cataract
}

\author{
Xiaochun Li $\mathbb{D},{ }^{1,2}$ Xiaoguang Cao $\mathbb{D}^{1},{ }^{1}$ Yingying Yu $\mathbb{D},{ }^{1}$ and Yongzhen Bao $\mathbb{D}^{1}$ \\ ${ }^{1}$ Department of Ophthalmology, Peking University People's Hospital; Eye Diseases and Optometry Institute; Beijing Key Laboratory \\ of Diagnosis and Therapy of Retinal and Choroid Diseases, College of Optometry, Peking University Health Science Center, \\ 11\# Xizhimen South Street, Xicheng District, Beijing 100044, China \\ ${ }^{2}$ Department of Ophthalmology, Peking University International Hospital, 1\# Shengmingyuan Road, Life Science Park, \\ Changping District, Beijing 102206, China
}

Correspondence should be addressed to Yongzhen Bao; baoyongzhen@pkuih.edu.cn

Received 18 June 2021; Revised 13 September 2021; Accepted 11 October 2021; Published 12 November 2021

Academic Editor: Hai-Feng Pan

Copyright (C) 2021 Xiaochun Li et al. This is an open access article distributed under the Creative Commons Attribution License, which permits unrestricted use, distribution, and reproduction in any medium, provided the original work is properly cited.

\begin{abstract}
Purpose. The previous lab and clinical studies of the correlation between the ultraviolet B and age-related cataract (ARC) did not reach in the universal agreement, especially in different morphological types of ARC. It is important to systemically summarize those previous data of epidemiological studies, which might penetrate the relevance between three morphological types of ARC, cortical, nuclear, and posterior capsular (PSC), with sunlight exposure. Methods. PubMed, Web of Science, CNKI, Embase, and Cochrane were searched online. Data were extracted and recalculated, and quality check was performed by hand. Review Manager was used to perform the fixed effects meta-analysis on ARC and its morphological types. The highest exposed dose group was defined as the exposed group, and the lowest dose group as the control group as possible. Results. Finally, the number of analyzed studies was 31: 20 for ARC and twelve, eleven, and nine for the morphological types cortical, nuclear, and PSC, respectively. The pooled OR for ARC was 1.15 (range 1.00 43.78, 95\% CI 1.09 to 1.21). The cortical cataract revealed a slightly higher risk, and pooled OR was 1.03 (range 0.67 2.91, 95\% CI 1.02 to 1.03). But the pooled OR for nuclear and PSC were 1.00 (range $0.50 \sim 5.35,95 \%$ CI 1.00 to 1.00 ) and 0.99 (range $0.57 \sim 1.87,95 \%$ CI 0.95 to 1.01 ), respectively. Conclusions. The systemic analysis of epidemiological articles reported till now reveals a significantly increased risk of ARC for those exposed with more sunlight, especially the morphological type of cortical cataract.
\end{abstract}

\section{Introduction}

As the leading cause of blindness many years worldwide, age-related cataract (ARC) still induces the bilaterally blindness on estimated 17 million individuals [1]. The report of China's Ministry of Health showed that there were approximately four million cataract patients in China, with a half million diagnosed new cases annually. As the only effective treatment, the cataract extraction might not get a good result for every patient, due to the inexperienced surgeons and inappropriate postoperative care and refractive error, and even could not be available at some time $[2,3]$. Now, the cataract extraction could be the most frequent operation among Medicare beneficiaries similar in China (1042850 in 2009) and in the United States (3280966 operations in 2003 and
2004) [4]. Moreover, the China Disabled Persons' Federation reported that the cost of cataract surgeries was over three billion $\mathrm{RMB}$ each year. A previous study showed that a ten-year delay on the onset of cataract could reduce the half need of cataract extraction as much [5].

The etiology of cataract, the lens opacity, involved many factors. In these, ultraviolet radiation (UV) might be the most important one besides the aging. In animal models, UVB (UV at $280-315 \mathrm{~nm}$ ) could induce lens opacity. But as the previous epidemiological studies in human, the universal agreement has not been drawn and the controversial results were reported, especially in the three different morphological types (cortical, nuclear, and posterior capsular) of ARC. The risk of cortical cataract increased with the increasing or accumulated amount of UVB radiation exposure, 
reported by some studies. However, the epidemiological studies for the nuclear type of ARC reported the mutually contradictory results. Unfortunately, the epidemiological studies of posterior capsular cataract (PSC) were quite less than the others; a few studies thought that the UVB might have an effect on PSC [6-14]. As different morphological types (cortical, nuclear, and posterior capsular) of ARC have an inequable effect on the patients' visual function, the exploration of cataract morphological types might contribute to the increase in patients' quality of life.

To end the debate, a systematic review and metaanalysis were performed to assess the association between sunlight exposure with ARC and its three morphological types. We assumed that the exposure of sunlight was a risk factor for ARC. The discrepancy between those previous studies grew out of the differences of study population and methodology.

\section{Methods}

2.1. Research Project. We conduct a meta-analysis on the previous epidemiological literatures of cataract, based on the meta-analysis of observational studies in epidemiology (MOOSE) [15]. CNKI, Web of Science, PubMed, Embase, and Cochrane Library databases (up to 9 September 2021) were searched online and by hand for published articles. IRB/Ethics Committee ruled that approval was not required for this study. The methodology was partly referred [16].

2.2. Principle of Included and Excluded Articles. Articles that met the criteria would be selected: epidemiological study focused or partly focused on the correlation of ARC and sunlight exposure, whose odds ratio (OR) and 95\% CI could be extracted or recalculated. "UV exposure", "visible light exposure", and "blue light exposure" were considered the same as sunlight exposure. All studies, which only focused on the laboratory, such as case report, letter, and experimental study, would be excluded.

In the subtype cataract setting, the included studies were divided into ARC and its three morphological types, cortical cataract, nuclear cataract, and PSC. If the data in the included manuscript were represented as cortical cataract, nuclear cataract, or PSC, it would be used for the calculation of each subtype, cortical cataract, nuclear cataract, and PSC. If the data were mentioned as mixed cataract or "cataract" only, it would be used for the calculation of the ARC subtype.

2.3. Search Principle. There was no restriction about language. We searched PubMed, Web of Science, and CNKI using the terms "ARC", "risk OR incidence OR epidemiologic", and "sunlight OR UV OR ultraviolet OR blue light OR visible light”. The methodology was partly referred [16]. For the Embase and Cochrane Library databases, as the advanced search does not support the complicated terms, "Cataract AND visible light", "Cataract AND blue light", "Cataract AND sunlight", and "Cataract AND ultraviolet" were searched separately and the results were evaluated manually paper by paper. All articles, which could be extracted OR or had sufficient data to calculate OR, would be included in our study.
2.4. Data Extraction and Calculation. OR of the sunlight exposed/unexposed and their 95\% CI were extracted by one author (Xiaoguang Cao) from the included articles besides general information. We calculated the OR ourselves by the software, Review Manager 5.2.4 (Java 6) for the articles without presenting OR with the published data. The definition of dose groups was partly referred [16].

2.5. Quality Check. Two checklists were used for the methodological quality evaluation and separately for cross-sectional studies and cohort/case-control studies as those previous designs [16], respectively. The two checklists contain all 31 items pertaining to population selection, comparability, and ascertainment of outcomes as presented in Tables 1 and 2 .

2.6. Statistical Analysis. The Q-test was used to explore the heterogeneity between included studies. The $Z$-test was used for the pooled OR statistical significance. The correlation of sunlight exposure and ARC was evaluated with OR and 95\% CI. A $P$ value of less than 0.05 was considered to be statistically significant. Meta-analysis and metaregression were both performed using Review Manager 5.2.4 (Java 6). The methodology was partly referred [16].

\section{Results}

In included studies, thirty-one studies were included during the year of 1980 to 2020 . Table 3 shows the included studies in ARC and three subtypes. Tables 1 and 2 show the quality evaluation of included articles.

For the ARC, 20 studies were included [9, 17-35]. The results of fixed effects meta-analysis indicated a significantly increased risk of ARC in the more exposed group, with a pooled OR of 1.15 (range 1.00 43.78, 95\% CI 1.09 to 1.21 , as Figure 1(a). A forest plot with details is presented in Figure $1(\mathrm{a})$ is asymmetric. And the result of random effects meta-analysis indicated a pooled OR of 1.74 (95\% CI 1.41 to 2.16) as shown in Figure 1(c).

3.1. Analysis of Subtype. In cortical cataract, twelve studies were included $[6,8,18,19,24,36-42]$. The results of the fixed effects meta-analysis indicated a slight increased risk of cortical cataract in the more exposed group than in other ARC subtype, with a pooled OR of 1.03 (range 0.67 2.91, 95\% CI 1.02 to 1.03, as Figure 2(a). A forest plot with details is presented in Figure 2(a). The funnel plot (Figure 2(b)) is borderline asymmetric. And the result of random effects meta-analysis indicated a pooled OR of 1.17 (95\% CI 1.01 to 1.36) as shown in Figure 2(c).

In nuclear cataract, eleven studies were included $[8,10$, $18,19,24,37,39-43]$. The results of the fixed effects metaanalysis did not indicate a significantly increased risk of nuclear cataract in the more exposed group, with a pooled OR of 1.00 (range $0.50 \sim 5.35,95 \%$ CI 1.00 to 1.00, Figure 3(a)). A forest plot with details is presented in Figure 3(a). The funnel plot (Figure 3(b)) is symmetric. And the result of random effects meta-analysis indicated a pooled OR of 1.01 (95\% CI 0.98 to 1.04 as shown in Figure 3(c). 
TABLE 1: Joanna Briggs Institute critical appraisal for the cross-sectional study.

\begin{tabular}{|c|c|c|c|c|c|c|c|c|c|}
\hline Author & 1 & 2 & 3 & 4 & 5 & 6 & 7 & 8 & 9 \\
\hline McCarty 2000 & $\mathrm{~N}$ & $\mathrm{Y}$ & $\mathrm{N}$ & $\mathrm{Y}$ & Y & $\mathrm{N}$ & $\mathrm{N}$ & $\mathrm{Y}$ & 1 \\
\hline McCarty 1999 & $\mathrm{Y}$ & $\mathrm{Y}$ & $\mathrm{N}$ & $\mathrm{Y}$ & $\mathrm{Y}$ & $\mathrm{N}$ & & $\mathrm{Y}$ & \\
\hline West 1998 & $\mathrm{~N}$ & $\mathrm{Y}$ & $\mathrm{N}$ & $\mathrm{Y}$ & $\mathrm{Y}$ & $\mathrm{N}$ & $\mathrm{N}$ & $\mathrm{Y}$ & \\
\hline Taylor 1988 & $\mathrm{~N}$ & $\mathrm{Y}$ & $\mathrm{N}$ & $\mathrm{Y}$ & $\mathrm{Y}$ & $\mathrm{N}$ & $\mathrm{N}$ & $\mathrm{Y}$ & $\mathrm{Y}$ \\
\hline Delcourt 2000 & $\mathrm{~N}$ & $\mathrm{Y}$ & $\mathrm{N}$ & $\mathrm{Y}$ & $\mathrm{Y}$ & $\mathrm{N}$ & $\mathrm{N}$ & $\mathrm{Y}$ & $\mathrm{Y}$ \\
\hline Dherani 2008 & $\mathrm{~N}$ & Y & $\mathrm{N}$ & $\mathrm{Y}$ & $\mathrm{Y}$ & $\mathrm{N}$ & $\mathrm{N}$ & $\mathrm{Y}$ & $\mathrm{Y}$ \\
\hline Hayashi 1998 & $\mathrm{~N}$ & Y & $\mathrm{N}$ & $\mathrm{Y}$ & $\mathrm{Y}$ & $\mathrm{N}$ & $\mathrm{N}$ & $\mathrm{Y}$ & $\mathrm{Y}$ \\
\hline Megbele 2012 & $\mathrm{~N}$ & $\mathrm{Y}$ & $\mathrm{N}$ & $\mathrm{Y}$ & $\mathrm{Y}$ & $\mathrm{N}$ & $\mathrm{N}$ & $\mathrm{Y}$ & $\mathrm{Y}$ \\
\hline Moise 2012 & $\mathrm{~N}$ & $\mathrm{Y}$ & $\mathrm{N}$ & $\mathrm{Y}$ & $\mathrm{Y}$ & $\mathrm{N}$ & $\mathrm{N}$ & $\mathrm{Y}$ & $\mathrm{Y}$ \\
\hline Paula 2006 & $\mathrm{~N}$ & $\mathrm{Y}$ & $\mathrm{N}$ & $\mathrm{Y}$ & $\mathrm{Y}$ & $\mathrm{N}$ & $\mathrm{N}$ & $\mathrm{Y}$ & $\mathrm{Y}$ \\
\hline Tarwadi 2011 & $\mathrm{~N}$ & $\mathrm{Y}$ & $\mathrm{N}$ & $\mathrm{Y}$ & $\mathrm{Y}$ & $\mathrm{N}$ & $\mathrm{N}$ & $\mathrm{Y}$ & $\mathrm{Y}$ \\
\hline Delcourt 1993 & $\mathrm{~N}$ & $\mathrm{Y}$ & $\mathrm{N}$ & $\mathrm{Y}$ & $\mathrm{Y}$ & $\mathrm{N}$ & $\mathrm{N}$ & $\mathrm{Y}$ & $\mathrm{Y}$ \\
\hline Delavar 2018 & $\mathrm{~N}$ & $\mathrm{Y}$ & $\mathrm{N}$ & $\mathrm{Y}$ & $\mathrm{Y}$ & $\mathrm{Y}$ & $\mathrm{N}$ & $\mathrm{Y}$ & $\mathrm{Y}$ \\
\hline Vashist 2020 & $\mathrm{Y}$ & $\mathrm{Y}$ & $\mathrm{N}$ & $\mathrm{Y}$ & $\mathrm{Y}$ & $\mathrm{N}$ & $\mathrm{N}$ & $\mathrm{Y}$ & $\mathrm{Y}$ \\
\hline AREDS 2001 & $\mathrm{~N}$ & $\mathrm{Y}$ & $\mathrm{N}$ & $\mathrm{Y}$ & $\mathrm{Y}$ & $\mathrm{Y}$ & $\mathrm{N}$ & $\mathrm{Y}$ & $\mathrm{Y}$ \\
\hline Cruickshanks 1992 & $\mathrm{~N}$ & $\mathrm{Y}$ & $\mathrm{N}$ & $\mathrm{Y}$ & $\mathrm{Y}$ & $\mathrm{Y}$ & $\mathrm{N}$ & $\mathrm{Y}$ & $\mathrm{Y}$ \\
\hline Katoh 2001 & $\mathrm{~N}$ & $\mathrm{Y}$ & $\mathrm{N}$ & $\mathrm{Y}$ & $\mathrm{Y}$ & $\mathrm{Y}$ & $\mathrm{N}$ & $\mathrm{Y}$ & $\mathrm{Y}$ \\
\hline Klein 2010 & $\mathrm{~N}$ & $\mathrm{Y}$ & $\mathrm{N}$ & $\mathrm{Y}$ & $\mathrm{Y}$ & $\mathrm{Y}$ & $\mathrm{N}$ & $\mathrm{Y}$ & $\mathrm{Y}$ \\
\hline Tang 2015 & $\mathrm{Y}$ & $\mathrm{Y}$ & $\mathrm{N}$ & $\mathrm{Y}$ & $\mathrm{Y}$ & $\mathrm{Y}$ & $\mathrm{N}$ & $\mathrm{Y}$ & $\mathrm{Y}$ \\
\hline Miyashita 2019 & $\mathrm{~N}$ & $\mathrm{Y}$ & $\mathrm{N}$ & $\mathrm{Y}$ & $\mathrm{Y}$ & $\mathrm{Y}$ & $\mathrm{N}$ & $\mathrm{Y}$ & \\
\hline
\end{tabular}

1: was the study based on a random or pseudorandom sample? 2 : were the criteria for inclusion in the sample clearly defined? 3 : were confounding factors identified and strategies to deal with them stated? 4: were outcomes assessed using objective criteria? 5: if comparisons are being made, was there sufficient description of the groups? 6: was follow-up carried out over a sufficient time period? 7: were the outcomes of people who withdrew described and included in the analysis? 8: were outcomes measured in a reliable way? 9: was appropriate statistical analysis used? $\mathrm{N}$ : no; Y: yes.

In PSC, nine studies were included $[8,18,19,24,37$, 39-42]. The results of the fixed effects meta-analysis did not indicate a significantly increased risk of PSC in the more exposed group, with a pooled OR of 0.99 (range 0.57 1.87, 95\% CI 0.95 to 1.01, as Figure 4(a)). A forest plot with details is presented in Figure 4(a). The funnel plot (Figure 4(b)) is symmetric. And the result of random effects meta-analysis indicated a pooled OR of 0.99 (95\% CI 0.88 to 1.12) as shown in Figure 4(c).

\section{Discussion}

As the leading cause of blindness, the etiology of ARC keeps dimness. Although the experimental evidence of sunlight, especially UVB-induced damage of lens epithelial cell and crystallin, seemed sufficient as follows, epidemiological evidence was unstable. The involvement of oxidative stress in the development of cataract has been researched and discussed for years [44]. Many previous studies had shown that the ultraviolet radiation could induce the apoptosis of lens epithelial cells, through the cell sign pathway of caspase3/Bcl-2/Bax [45]. Specific crystallins might play some important roles in the process [46]. Advance glycation end
TABle 2: Joanna Briggs Institute critical appraisal for the cohort/case-control study.

\begin{tabular}{lccccccccc}
\hline Author & 1 & 2 & 3 & 4 & 5 & 6 & 7 & 8 & 9 \\
\hline Burton 1997 & Y & Y & Y & Y & Y & N & N & Y & Y \\
Collman 1988 & N & Y & Y & Y & Y & N & N & Y & Y \\
Pastor-Valero 2007 & N & Y & Y & Y & Y & N & N & Y & Y \\
Saadat 2006 & N & Y & Y & Y & Y & N & N & Y & Y \\
Sreenivas 1999 & Y & Y & Y & Y & Y & N & N & Y & Y \\
Taylor 1980 & N & Y & Y & Y & Y & N & N & Y & Y \\
Theodoropoulou 2011 & N & Y & Y & Y & Y & N & N & Y & Y \\
Wong 1993 & N & Y & Y & Y & Y & N & N & Y & Y \\
Yu 2016 & Y & Y & Y & Y & Y & N & N & Y & Y \\
Leske1991 & N & Y & Y & Y & Y & N & N & Y & Y \\
Neale 2003 & N & Y & Y & Y & Y & N & N & Y & Y \\
\hline
\end{tabular}

1 : is the sample representative of patients in the population as a whole? 2: are the patients at a similar point in the course of their condition/illness? 3: has bias been minimized in relation to selection of cases and of controls? 4: are confounding factors identified and strategies to deal with them stated? 5: are outcomes assessed using objective criteria? 6: was follow-up carried out over a sufficient time period? 7: were the outcomes of people who withdrew described and included in the analysis? 8: were outcomes measured in a reliable way? 9: was appropriate statistical analysis used? N: no; Y: yes.

TABLE 3: The included studies for the meta-analysis of the association between sunlight and age-related cataract (ARC).

\begin{tabular}{lcccc}
\hline Public year & $\begin{array}{c}\text { Before } \\
2000\end{array}$ & $\begin{array}{c}2000 \text { to } \\
2009\end{array}$ & $\begin{array}{c}2010 \text { to } \\
\text { now }\end{array}$ & Sum \\
\hline Age-related cataract & 7 & 5 & 8 & 20 \\
Cortical cataract & 4 & 5 & 3 & 12 \\
$\begin{array}{l}\text { Nuclear cataract } \\
\text { Posterior capsular }\end{array}$ & 5 & 3 & 3 & 11 \\
cataract & 4 & 2 & 3 & 9 \\
Total & 11 & 9 & 11 & 31 \\
\hline
\end{tabular}

products and plasma membrane calcium ATPasel are important contributors during cataract development [47].

Even numbers of epidemiologic studies on ARC have been published, and there is no meta-analysis to explore the association between ARC and sunlight exposure until our study, especially for different morphological types. The significant pooled OR of 1.15 (95\% CI 1.09 to 1.21 ) is an evidence for our conjecture, in which the sunlight exposure would increase the prevalence of ARC.

ARC could be classified as three types in morphology, cortical, nuclear, and PSC [48], and cortical cataract counted as $60 \%-70 \%$ in ARC. Previous studies showed that the prevalence of ARC had obvious geographical difference. For example, the prevalence of ARC in people aged 40 years and older was 30\% in Victoria, Australia, and the proportion of cortical cataract increased with the decreased latitude [6]. The study in Shunyi Beijing, China, showed that the prevalence of ARC in people aged 50 years and older was $23.31 \%[49]$. 


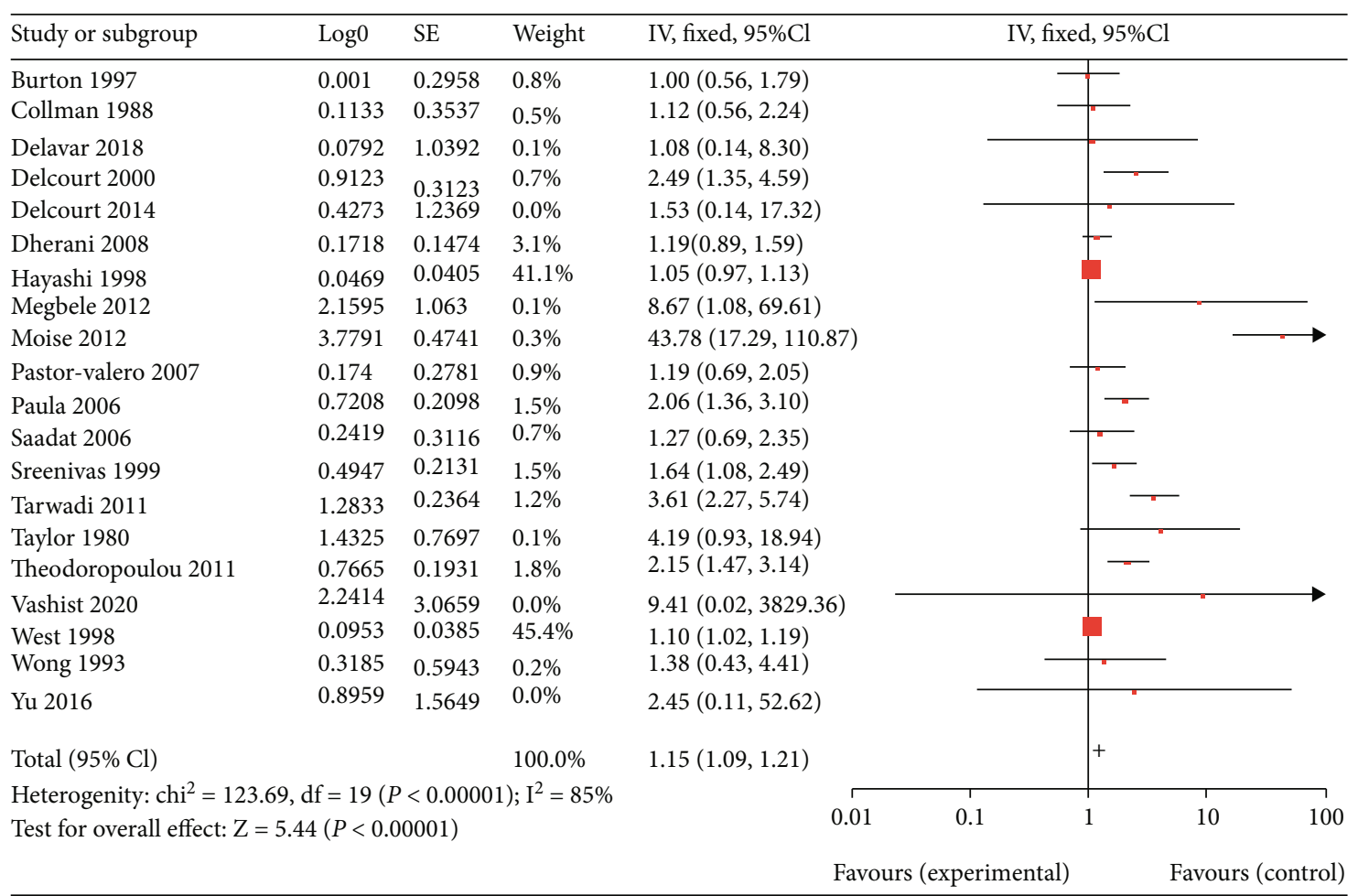

(a)

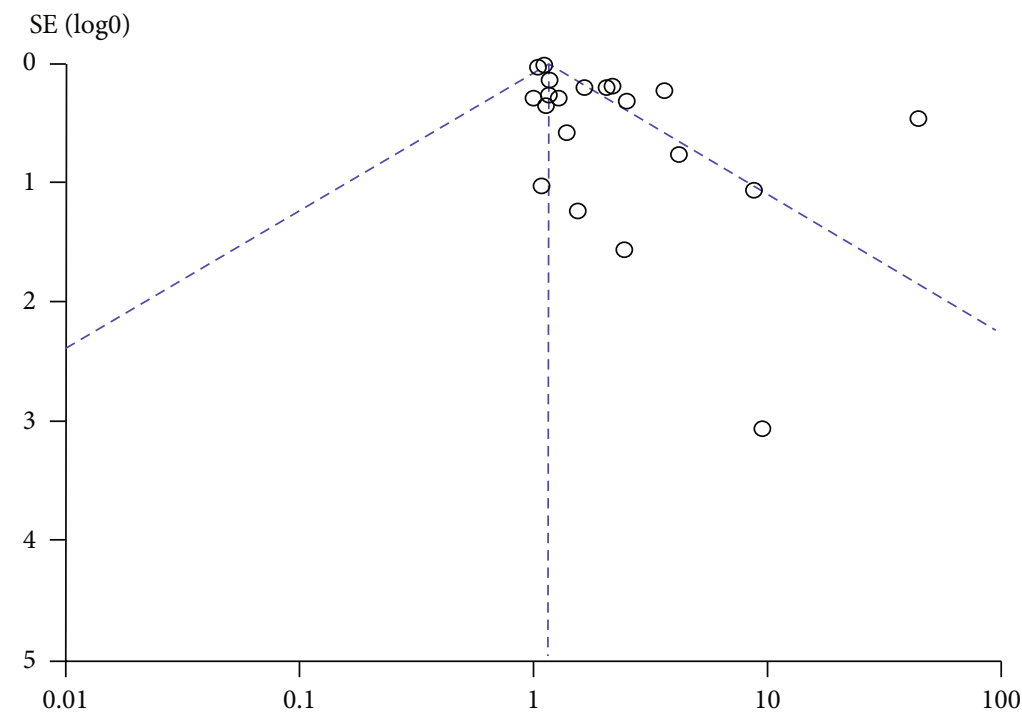

(b)

Figure 1: Continued. 


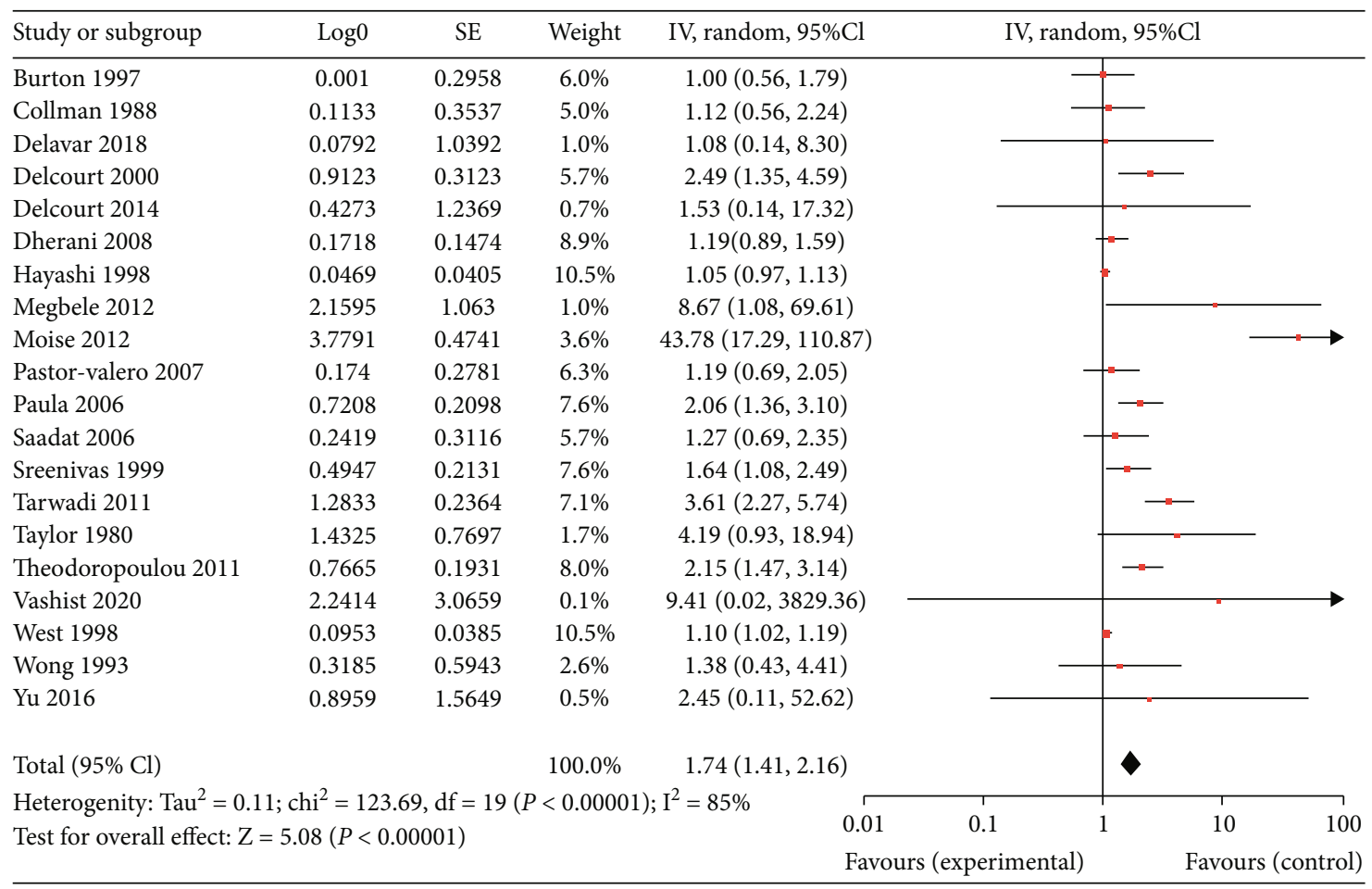

(c)

FIGURE 1: The result of meta-analysis for age-related cataract (ARC): forest plot of fixed effects meta-analysis (a); funnel plot of fixed effects meta-analysis (b); forest plot of random effects meta-analysis (c).

Our study indicated that the sunlight exposure had a slightly higher risk on the cortical cataract in the three types of ARC (pooled OR 1.03, 95\% CI 1.02 to 1.03 ). However, the sunlight exposure did not have influence on the nuclear cataract (pooled OR 1.00, 95\% CI 1.00 to 1.00) or PSC (pooled OR $0.99,95 \%$ CI 0.95 to 1.01 ).

The influence of sunlight exposure on cortical cataract is consistent with the previous epidemiological studies. Some studies already showed the risk of cortical cataract increased by the increasing amount of UVB radiation exposure, with a dose-dependent relationship [6-11]. At the same time, the damage of UVB on lens was a cumulative effect. McCarty and Taylor thought the development of cortical cataract associated with UVB [7]; the ocular UVB exposure could explain the $10 \%$ of cortical cataract [6]. Moreover, West et al. thought that not only was the risk of cortical cataract increased with UVB radiation but also the damage on lens was a cumulative effect [9]. The study of Taylor in Chesapeake Bay showed that in 838 watermen, the cataract patients had more $21 \%$ UVB exposure than the controls. UV radiation increases 1 time, and the risk of cortical cataract increased 1.6 times. The risk of cortical cataract for the highest radiation exposure in the investigated people was 3.3 times that for the lowest radiation exposure $[10,11]$.

For nuclear cataract, the results of epidemiological studies were mutually contradictory. McCarty et al. believed that the risk factors of nuclear cataract included ocular UVB exposure [8], whereas Taylor thought that UVB exposure had no effect on the nuclear cataract $[10,11]$. The study performed by Hayashi et al. in Japan showed that the opacity of lens was related to the exposure dose of UVB, and the effect of UV on the nuclear cataract was stronger than that on cortical cataract [12]. One interesting study found a significant relationship between UV dosage and color naming: in lowUV localities, languages generally have the word "blue"; in high-UV areas, languages without "blue" prevail. It might be explained by the density change of lens induced by UV exposure [13]. Our study might end the debate, as a pooled OR of 1.00 (95\% CI 1.00 to 1.00 ) indicated that the exposure of sunlight has no effect on the nuclear cataract, either harmful or protective.

The epidemiological studies of PSC were quite less than the others. McCarty and Taylor and Bochow et al. both thought that UVB radiation might have an effect on the incident of PSC $[7,14]$. Our study showed that the pooled OR of sunlight exposure on PSC was 0.99 (95\% CI 0.95 to 1.01), which indicated that the sunlight exposure had no effect on PSC.

Although the result of our study was consistent with the previous epidemiological studies of UVB exposure and incidence of ARC, it is premature to exclude UVA or even visible light in the etiology of ARC, especially cortical cataracts [50]. Exposure to intense artificial light and sunlight either caused or exacerbated age-related ocular diseases [51]. One previous study showed that long UVB and UVA might be involved in age-related alterations of the human lens and cataract formation [52]. The study by Zigman found that UVA might be easier inducing ARC than UVB [53].

As there is no universal accepted criterion for the definition of sunlight exposure, its effect on the prevalence of ARC cannot be calculated accurately, and overestimation and 


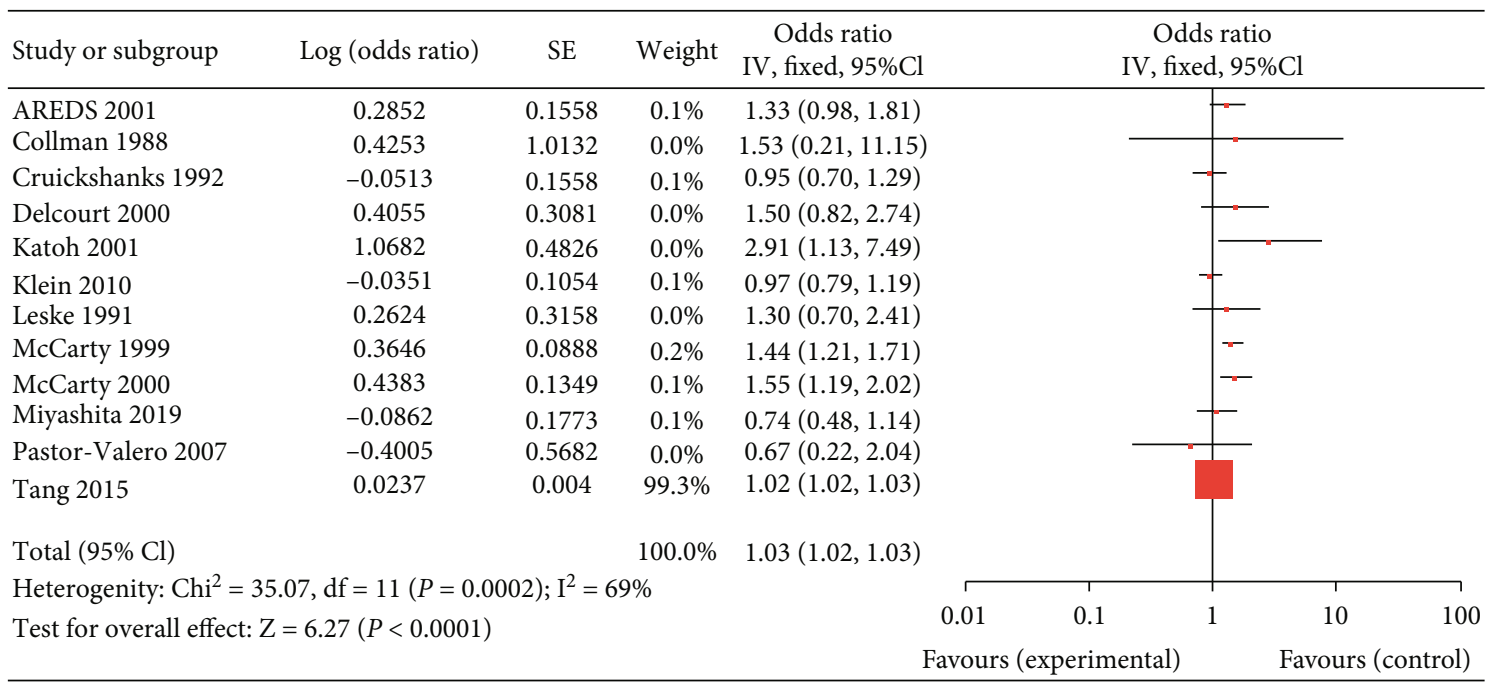

(a)

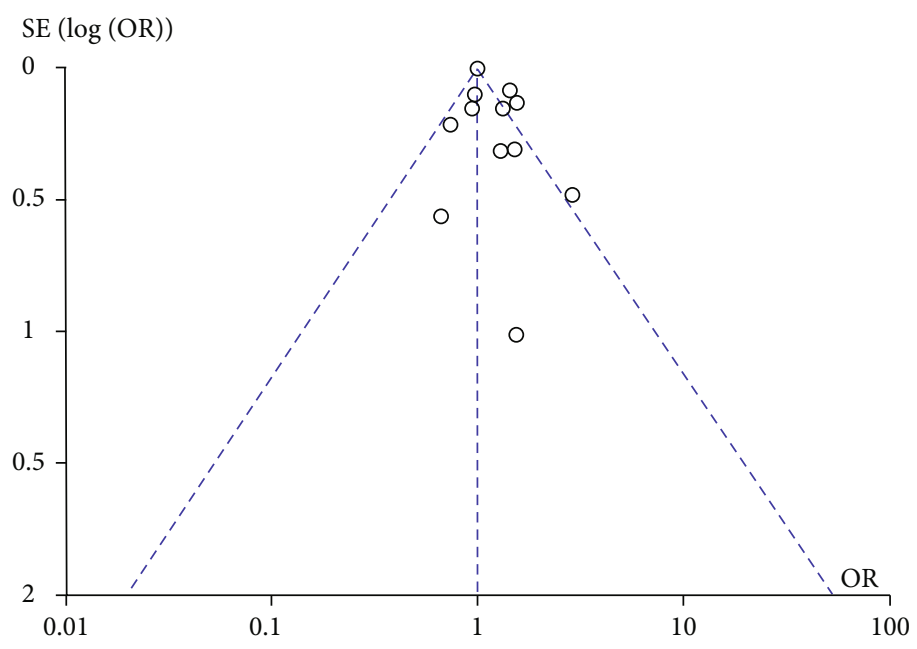

(b)

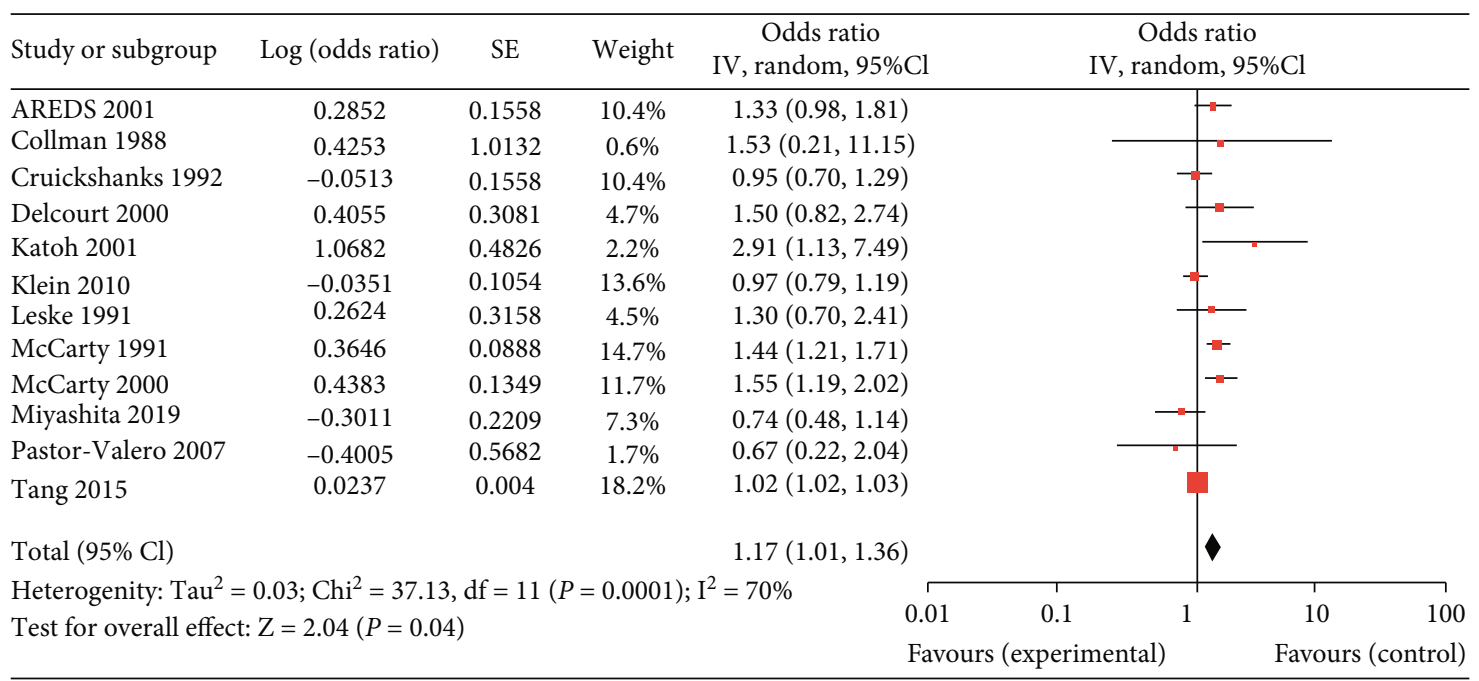

(c)

FIGURE 2: The result of meta-analysis for the subtype, cortical cataract of age-related cataract (ARC): forest plot of fixed effects meta-analysis (a); funnel plot of fixed effects meta-analysis (b); forest plot of random effects meta-analysis (c). 


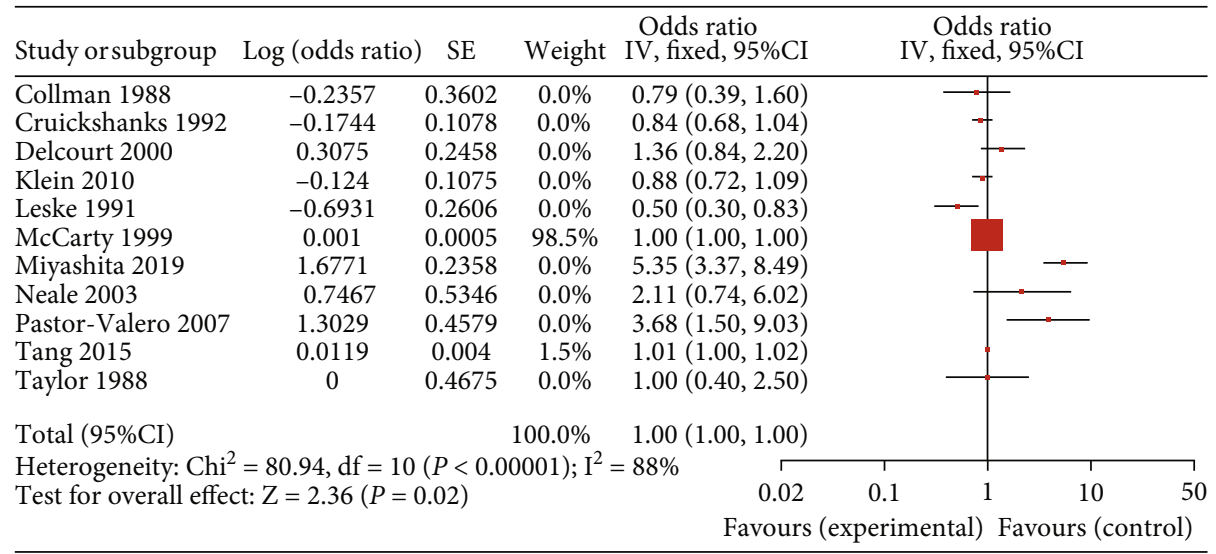

(a)

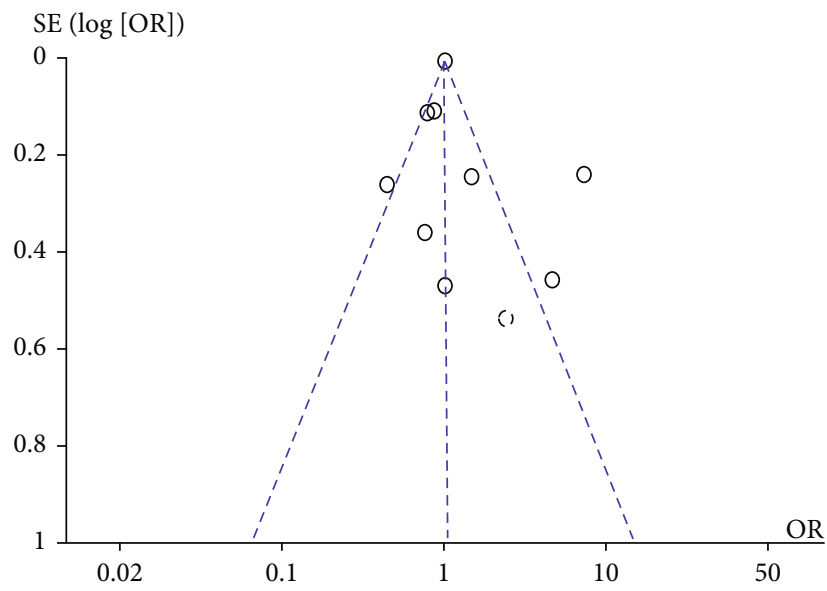

(b)

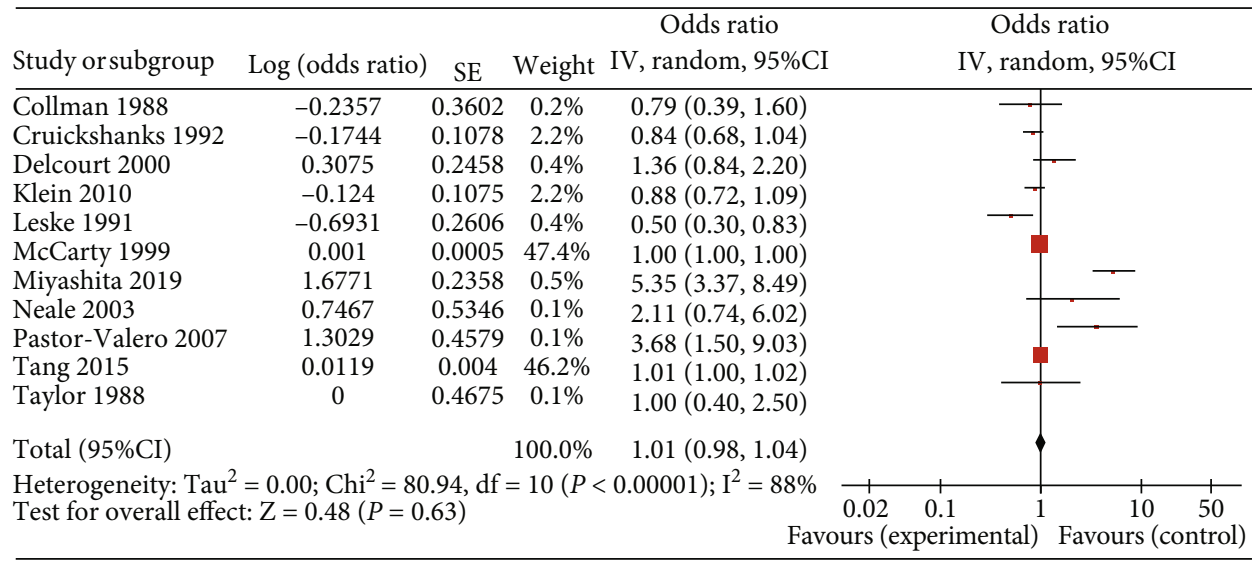

(c)

FIGURE 3: The result of meta-analysis for the subtype, nuclear cataract of age-related cataract (ARC): forest plot of fixed effects meta-analysis (a); funnel plot of fixed effects meta-analysis (b); forest plot of random effects meta-analysis (c).

underestimation could be possible in those previous studies. A frequently used method is the documented occupation and answer questionnaire to mark the exposure group and control group $[22,23,30,36]$. Another method is the geographic division, whose ultraviolet radiation would be the exposure for the groups [17]. Those defects of definition might lead to the overlapping of sunlight exposure. On the other hand, as the living habits are different and the sunlight exposure in the leisure time is also quite different, even some methods could be corrected partly [19]. Finally, with popular sunlight-protecting equipment, such as sunglasses and hat, the exposure of sunlight could not be measured or estimated correctly.

The restriction of our meta-analysis should be noted. The possible underestimation or overestimation of pooled 


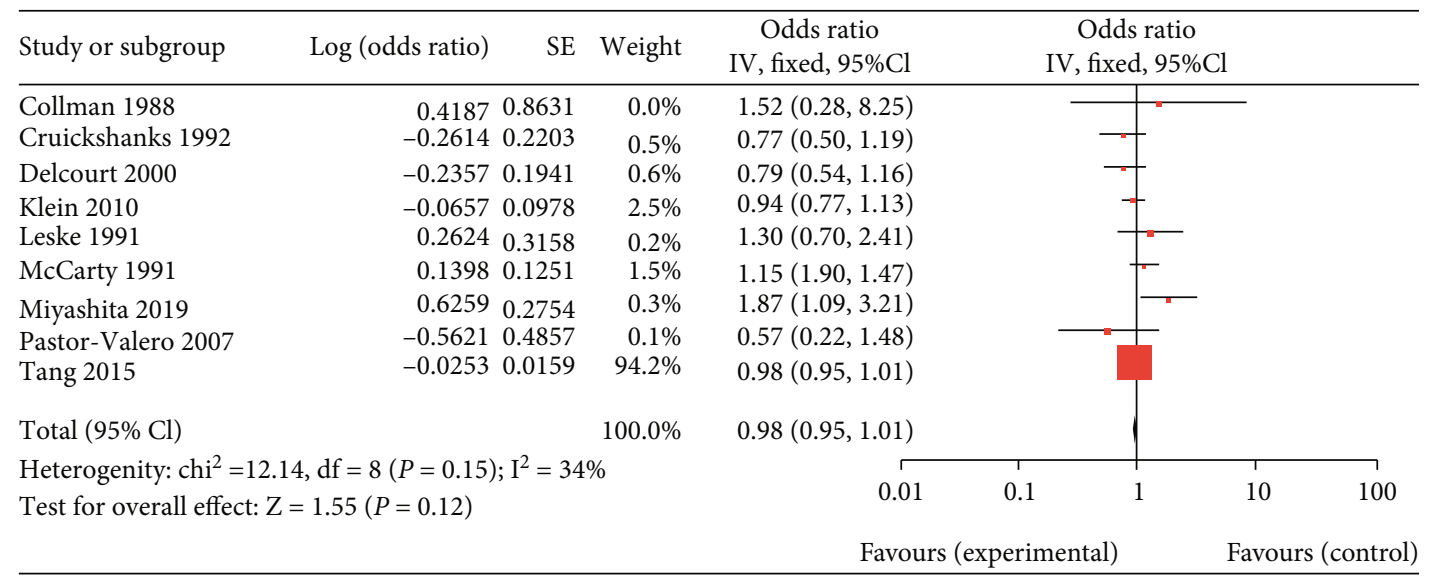

(a)

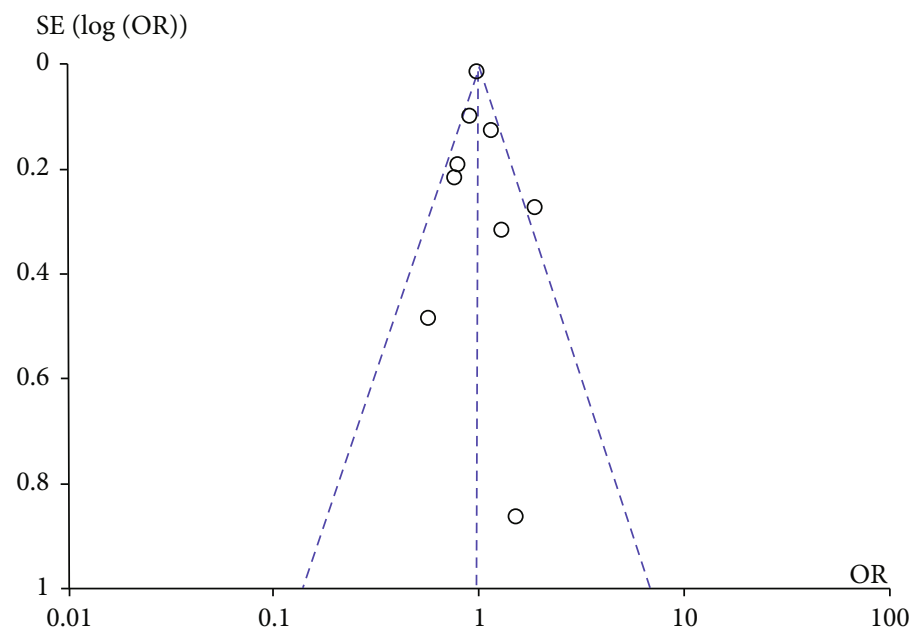

(b)

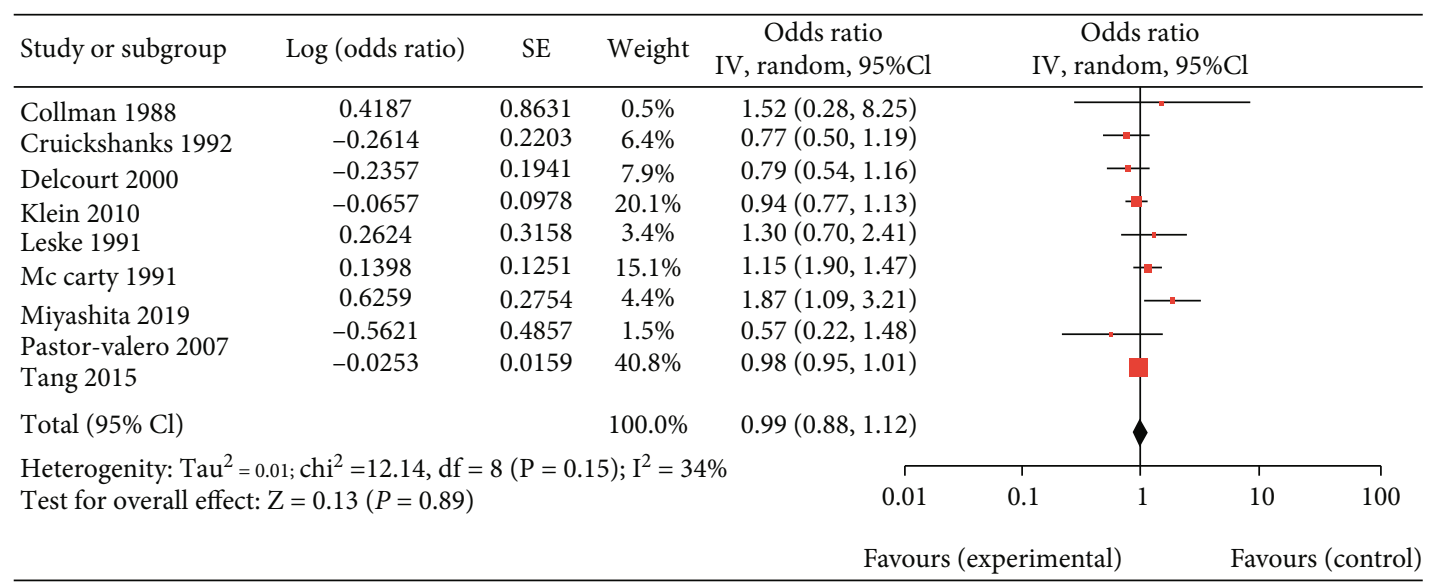

(c)

FIGURE 4: The result of meta-analysis for the subtype, posterior capsular cataract of age-related cataract (ARC): forest plot of fixed effects meta-analysis (a); funnel plot of fixed effects meta-analysis (b); forest plot of random effects meta-analysis (c).

OR could not be ignored due to the various methodological limitations and grouping criteria. And as the language limitation, the eligible studies, only written in English and Chinese, could be included, which might induce a bias. Moreover, the funnel plots in our analysis seemed asymmet- rical. Despite this faultiness, the meta-analysis of our study makes an important contribution to the etiology of ARC, as the first study to explore the possible relationship between sunlight exposure and ARC, especially for these three morphological types, cortical, nuclear, and PSC. 


\section{Conclusion}

The meta-analysis and systemic review of epidemiological studies published till now revealed that the higher exposure of sunlight would increase the risk of ARC significantly. The advanced analysis of morphological types showed that the high level of sunlight exposure is slightly increased risk on the cortical cataract, but the high sunlight exposure has no risk effect on the nuclear or PSC. The differences in the study population and the methodological quality and criterion of the studies had a potential effect on heterogeneity.

\section{Data Availability}

The clinic data used to support the findings of this study are included within the article.

\section{Ethical Approval}

The study was in accordance with the tenets of the Declaration of Helsinki and has been approved by the institutional review board of Peking University People's Hospital.

\section{Consent}

Written informed consent was not needed for our study.

\section{Conflicts of Interest}

The authors declare that they have no conflicts of interest.

\section{Authors' Contributions}

All authors had made substantial contributions to this manuscript. Xiaochun Li and Xiaoguang Cao contribute equally to the writing of this article and are co-first authors.

\section{Acknowledgments}

This study was supported by the National Natural Science Foundation of China (NSFC, no. 21173012).

\section{References}

[1] A. Foster and G. J. Johnson, "Magnitude and causes of blindness in the developing world," International Ophthalmology, vol. 14, no. 3, pp. 135-140, 1990.

[2] L. Dandona, R. Dandona, T. J. Naduvilath et al., "Populationbased assessment of the outcome of cataract surgery in an urban population in southern India," American Journal of Ophthalmology, vol. 127, no. 6, pp. 650-658, 1999.

[3] M. He, J. Xu, S. Li, K. Wu, S. R. Munoz, and L. B. Ellwein, "Visual acuity and quality of life in patients with cataract in Doumen County, China," Ophthalmology, vol. 106, no. 8, pp. 1609-1615, 1999.

[4] L. Keay, E. W. Gower, S. D. Cassard, J. M. Tielsch, and O. D. Schein, "Postcataract surgery endophthalmitis in the United States: analysis of the complete 2003 to 2004 Medicare database of cataract surgeries," Ophthalmology, vol. 119, no. 5, pp. 914-922, 2012.
[5] C. Kupfer, "Bowman lecture. The conquest of cataract: a global challenge," Transactions of the Ophthalmological Societies of the United Kingdom, vol. 104, pp. 1-10, 1985.

[6] C. A. McCarty, M. B. Nanjan, and H. R. Taylor, "Attributable risk estimates for cataract to prioritize medical and public health action," Investigative Ophthalmology \& Visual Science, vol. 41, no. 12, pp. 3720-3725, 2000.

[7] C. A. McCarty and H. R. Taylor, "A review of the epidemiologic evidence linking ultraviolet radiation and cataracts," Developments in Ophthalmology, vol. 35, pp. 21-31, 2002.

[8] C. A. McCarty, B. N. Mukesh, C. L. Fu, and H. R. Taylor, "The epidemiology of cataract in Australia," American Journal of Ophthalmology, vol. 128, no. 4, pp. 446-465, 1999.

[9] S. K. West, D. D. Duncan, B. Muñoz et al., "Sunlight exposure and risk of lens opacities in a population-based study: the Salisbury Eye Evaluation project," JAMA, vol. 280, no. 8, pp. 714-718, 1998.

[10] H. R. Taylor, S. K. West, F. S. Rosenthal et al., "Effect of ultraviolet radiation on cataract formation," The New England Journal of Medicine, vol. 319, no. 22, pp. 1429-1433, 1988.

[11] H. R. Taylor, "Ultraviolet radiation and the eye: an epidemiologic study," Transactions of the American Ophthalmological Society, vol. 87, pp. 802-853, 1989.

[12] L. C. Hayashi, S. Hayashi, K. Yamaoka, N. Tamiya, M. Chikuda, and E. Yano, "Ultraviolet B exposure and type of lens opacity in ophthalmic patients in Japan," Science of the total environment, vol. 302, no. 1-3, pp. 53-62, 2003.

[13] D. T. Lindsey and A. M. Brown, "Color naming and the phototoxic effects of sunlight on the eye," Psychological Science, vol. 13, no. 6, pp. 506-512, 2002.

[14] T. W. Bochow, S. K. West, A. Azar, B. Munoz, A. Sommer, and H. R. Taylor, "Ultraviolet light exposure and risk of posterior subcapsular cataracts," Archives of Ophthalmology, vol. 107, no. 3, pp. 369-372, 1989.

[15] D. F. Stroup, J. A. Berlin, S. C. Morton et al., "Meta-analysis of observational studies in Epidemiology: A proposal for Reporting," JAMA, vol. 283, no. 15, pp. 2008-2012, 2000.

[16] G. Y. Sui, G. C. Liu, G. Y. Liu et al., "Is sunlight exposure a risk factor for age-related macular degeneration? A systematic review and meta-analysis," The British Journal of Ophthalmology, vol. 97, no. 4, pp. 389-394, 2013.

[17] M. Burton, E. Fergusson, A. Hart, K. Knight, D. Lary, and C. Liu, "The prevalence of cataract in two villages of northern Pakistan with different levels of ultraviolet radiation," Eye, vol. 11, no. 1, pp. 95-101, 1997.

[18] G. W. Collman, D. L. Shore, C. M. Shy, H. Checkoway, and A. S. Luria, "Sunlight and other risk factors for cataracts: an epidemiologic study," American Journal of Public Health, vol. 78, no. 11, pp. 1459-1462, 1988.

[19] C. Delcourt, I. Carrière, A. Ponton-Sanchez, A. Lacroux, M. J. Covacho, and L. Papoz, "Light exposure and the risk of cortical, nuclear, and posterior subcapsular cataracts," Archives of Ophthalmology, vol. 118, no. 3, pp. 385-392, 2000.

[20] M. Dherani, G. V. S. Murthy, S. K. Gupta et al., "Blood levels of vitamin $\mathrm{C}$, carotenoids and retinol are inversely associated with cataract in a North Indian population," Investigative Ophthalmology \& Visual Science, vol. 49, no. 8, pp. 3328-3335, 2008.

[21] L. C. Hayashi, N. Tamiya, and E. Yano, "Correlation between UVB irradiation and the proportion of cataract-an epidemiological study based on a nationwide patient survey in Japan," Industrial Health, vol. 36, no. 4, pp. 354-360, 1998. 
[22] Y. Megbele, K. B. Lam, and S. Sadhra, "Risks of cataract in Nigerian metal arc welders," Occupational Medicine (London), vol. 62, no. 5, pp. 331-336, 2012.

[23] M. M. Moise, L. M. Benjamin, T. M. Doris, K. N. Dalida, and N. O. Augustin, "Role of Mediterranean diet, tropical vegetables rich in antioxidants, and sunlight exposure in blindness, cataract and glaucoma among African type 2 diabetics," International Journal of Ophthalmology, vol. 5, no. 2, pp. 231-237, 2012.

[24] M. Pastor-Valero, A. E. Fletcher, B. L. de Stavola, and V. Chaqués-Alepúz, "Years of sunlight exposure and cataract: a case-control study in a Mediterranean population," $B M C$ Ophthalmology, vol. 7, no. 1, p. 18, 2007.

[25] J. S. Paula, F. Thorn, and A. A. Cruz, "Prevalence of pterygium and cataract in indigenous populations of the Brazilian Amazon rain forest," Eye, vol. 20, no. 5, pp. 533-536, 2006.

[26] M. Saadat and M. Farvardin-Jahromi, "Occupational sunlight exposure, polymorphism of glutathione S-transferase M1, and senile cataract risk," Occupational and Environmental Medicine, vol. 63, no. 7, pp. 503-504, 2006.

[27] V. Sreenivas, A. K. Prabhakar, S. S. Badrinath et al., "A rural population based case-control study of senile cataract in India," Journal of Epidemiology, vol. 9, no. 5, pp. 327-336, 1999.

[28] K. V. Tarwadi and V. V. Agte, "Interrelationships between nutritional status, socioeconomic factors, and lifestyle in Indian cataract patients," Nutrition, vol. 27, no. 1, pp. 40-45, 2011.

[29] H. R. Taylor, "The prevalence of corneal disease and cataracts in Australian aborigines in Northwestern Australia," Australian Journal of Ophthalmology, vol. 8, no. 4, pp. 289-301, 1980.

[30] S. Theodoropoulou, P. Theodossiadis, E. Samoli, I. Vergados, P. Lagiou, and A. Tzonou, "The epidemiology of cataract: a study in Greece," Acta Ophthalmologica, vol. 89, no. 2, pp. e167-e173, 2011.

[31] L. Wong, S. C. Ho, D. Coggon et al., "Sunlight exposure, antioxidant status, and cataract in Hong Kong fishermen," Journal of Epidemiology and Community Health, vol. 47, no. 1, pp. 4649, 1993.

[32] C. Delcourt, A. Cougnard-Grégoire, M. Boniol et al., "Lifetime exposure to ambient ultraviolet radiation and the risk for cataract extraction and age-related macular degeneration: the Alienor Study," Investigative Ophthalmology \& Visual Science, vol. 55, no. 11, pp. 7619-7627, 2014.

[33] A. Delavar, D. M. Freedman, R. Velazquez-Kronen et al., "Ultraviolet radiation and incidence of cataracts in a nationwide US cohort," Ophthalmic Epidemiology, vol. 25, no. 5-6, pp. 403-411, 2018.

[34] P. Vashist, R. Tandon, G. V. S. Murthy et al., “Association of cataract and sun exposure in geographically diverse populations of India: the CASE study. First Report of the ICMREYE SEE Study Group,” PLoS One, vol. 15, no. 1, 2020.

[35] J. M. Yu, D. Q. Yang, H. Wang et al., "Prevalence and risk factors of lens opacities in rural populations living at two different altitudes in China," International Journal of Ophthalmology, vol. 9, no. 4, pp. 610-616, 2016.

[36] Age-Related Eye Disease Study Research Group, "Risk factors associated with age-related nuclear and cortical cataract: a case-control study in the Age-Related Eye Disease Study, AREDS report no. 5," Ophthalmology, vol. 108, no. 8, pp. 1400-1408, 2001.
[37] K. J. Cruickshanks, B. E. Klein, and R. Klein, "Ultraviolet light exposure and lens opacities: the Beaver Dam Eye Study," American Journal of Public Health, vol. 82, no. 12, pp. 16581662, 1992.

[38] N. Katoh, F. Jonasson, H. Sasaki et al., "Cortical lens opacification in Iceland. Risk factor analysis - Reykjavik Eye Study," Acta Ophthalmologica Scandinavica, vol. 79, no. 2, pp. 154159, 2001.

[39] B. E. Klein, K. E. Lee, L. G. Danforth, T. M. Schaich, K. J. Cruickshanks, and R. Klein, "Selected sun-sensitizing medications and incident cataract," Archives of Ophthalmology, vol. 128, no. 8, pp. 959-963, 2010.

[40] M. C. Leske, L. T. Chylack Jr., and S. Y. Wu, "The lens opacities case-control Study," Archives of Ophthalmology, vol. 109, no. 2, pp. 244-251, 1991.

[41] Y. Tang, Y. Ji, X. Ye et al., "The association of outdoor activity and age-related cataract in a rural population of Taizhou Eye Study: phase 1 report," PLoS One, vol. 10, no. 8, 2015.

[42] H. Miyashita, N. Hatsusaka, E. Shibuya et al., "Association between ultraviolet radiation exposure dose and cataract in Han people living in China and Taiwan: a cross-sectional study," PLoS One, vol. 14, no. 4, 2019.

[43] R. E. Neale, J. L. Purdie, L. W. Hirst, and A. C. Green, "Sun exposure as a risk factor for nuclear cataract," Epidemiology, vol. 14, no. 6, pp. 707-712, 2003.

[44] J. Zhang, H. Yan, S. Löfgren, X. Tian, and M. F. Lou, "Ultraviolet radiation-induced cataract in mice: the effect of age and the potential biochemical mechanism," Investigative Ophthalmology \& Visual Science, vol. 53, no. 11, pp. 7276-7285, 2012.

[45] Y. Ji, L. Cai, T. Zheng et al., "The mechanism of UVB irradiation induced-apoptosis in cataract," Molecular and Cellular Biochemistry, vol. 401, no. 1-2, pp. 87-95, 2015.

[46] N. Schafheimer, Z. Wang, K. Schey, and J. King, "Tyrosine/cysteine cluster sensitizing human $\gamma \mathrm{D}$-crystallin to ultraviolet radiation-induced photoaggregation in vitro," Biochemistry, vol. 53, no. 6, pp. 979-990, 2014.

[47] M. Linetsky, C. T. Raghavan, K. Johar et al., "UVA lightexcited kynurenines oxidize ascorbate and modify lens proteins through the formation of advanced glycation end products," The Journal of Biological Chemistry, vol. 289, no. 24, pp. 17111-17123, 2014.

[48] O. Hockwin, "Cataract classification," Documenta Ophthalmologica, vol. 88, no. 3-4, pp. 263-275, 1994.

[49] J. Zhao, R. Sui, and L. Jia, "Prevalence of cataract and surgical coverage among adults aged 50 or above in Shunyi District of Beijing, China," Zhonghua Yan Ke Za Zhi, vol. 37, no. 1, pp. 3$8,2001$.

[50] J. Dillon, L. E. I. Zheng, J. C. Merriam, and E. R. Gaillard, "The optical properties of the anterior segment of the eye: implications for cortical cataract," Experimental Eye Research, vol. 68, no. 6, pp. 785-795, 1999.

[51] J. E. Roberts, “Ocular phototoxicity," Journal of Photochemistry and Photobiology. B, vol. 64, no. 2-3, pp. 136-143, 2001.

[52] O. Sommerburg, O. Ullrich, N. Sitte, D. von Zglinicki, W. Siems, and T. Grune, "Dose- and wavelength-dependent oxidation of crystallins by UV light-selective recognition and degradation by the 20 S proteasome," Free Radical Biology \& Medicine, vol. 24, no. 9, pp. 1369-1374, 1998.

[53] S. Zigman, "Environmental near-UV radiation and cataracts," Optometry and Vision Science, vol. 72, no. 12, pp. 899-901, 1995. 